\title{
Research Progress on Multicultural Nursing of Religion Believing Patient
}

\author{
Xuejun Liu*, Weili Ma and Liping Mo \\ Xinhua Hospital Affiliated to Shanghai Jiao Tong University School of Medicine, Shanghai 200092, China
}

\begin{abstract}
Multicultural nursing refers to the discussion and analysis of nations with different cultures in the world. It focuses on the research of different traditional lifestyles, the cognition to health and disease, and people's belief and value, and takes advantage of this knowledge for general and different nursing to the people of different nations. In the medical progress, patient with religion belief has different demands on the aspects of diet, custom, privacy and religion activities, etc. This paper summarizes the significance of the implementation of multicultural nursing to patient with religion beliefs and current situation of the development of religion nursing at home and abroad as following.
\end{abstract}

\author{
KEYWORDS \\ Multicultural nursing \\ Religion belief \\ Psychological comforting
}

\section{Introduction}

Religious belief encompasses people who believe a certain specific religion with unalterable belief as well as having converted wholeheartedly to worship and identify a sacred object (including specific dogmata and doctrine, etc.). This type of ideological belief and conversion runs through specific religion rites and activities, and it can be used to guide and normalize the behavior of oneself in secular society. It belongs to certain specific social ideology and cultural phenomenon.

\section{Multicultural nursing and religion-related concept} The concept of culture refers to the summation of material and spiritual wealth which is created by human being from social historical development [1]. Multicultural or multi-national culture, and different nations and cultural backgrounds create different codes of conduct which will lead different social development. Multicultural nursing refers to facing society and world, understanding patients' demands under different cultural backgrounds, providing

Copyright ๑ 2016 Xuejun Liu et al.

doi: 10.18686/jn.v5i3.13

Received: September 14, 2016; Accepted: November 6, 2016; Published online: December 29, 2016

This is an open-access article distributed under the terms of the Creative Commons Attribution Unported License (http://creativecommons.org/ licenses/by-nc/4.0/), which permits unrestricted use, distribution, and reproduction in any medium, provided the original work is properly cited.

${ }^{\star}$ Corresponding author: Xinhua Hospital Affiliated to Shanghai Jiao Tong University School of Medicine, Shanghai 200092, China. E-mail: wangx136@126.com high-level and comprehensive nursing according to different features, which is to permeate multiculturalism into nursing work, imposing comprehensive nursing to the patient for the sake of body recovery [2].

China is a multi-national country, and our patients hail from different areas, different nations, even from different countries and areas in the world. Different social environments and cultural backgrounds in which patients live determine the difference of their lifestyles, religious beliefs, values, etc. [3]. The fulfillment of their different nursing and cultural demands is a new issue that clinical nursing workers must treat well, including the key to discuss multicultural nursing. Providing multi- and quality nursing service to different patients is the need of the current pluralistic society [4].

\section{Religious influence on believer's hospitalized atti- tude and behavior}

As a result of differing religion customs, religious believers display different attitudes and behaviors when consulting the doctor.

The research result of researcher Andrea Phelps from Dana-Farber Cancer Institute [5] shows that the religious believer believes death is God's will; even though they neither expedite death nor adopt painful medical process in order to prolong their lives.

Some religious believers firmly believe that their body cannot accept the donation of blood from other people or even animals, therefore rejecting transfusion. A 16 years old boy from Oregon had lost his hospitalization opportunity and even his life, for his parents' religion belief which 
caused media and public opinion's attention from the whole of America [6]. Meanwhile, religious believers still keep to their religion customs, like prayer, and purification, when seeking medical service like limosis. The conventional nursing progress cannot fulfill religious believers' demands, thus only the popularization of multicultural nursing can fulfill the religious believer's demands in the nursing progress to a large extent.

\section{Research status of religion nursing}

About the religion nursing status at home, a research on psychotic patients' nursing work report by Chang Wanping [7] shows that patients with religious belief display varying degrees of religious impact on the aspects of treatment, hospitalization and medication compliance which always lead to the delay of early treatment. Therefore, we shall delve into customs of different nations and their demands in order to provide corresponding nursing to different nations, and narrow the gap with humanistic and geographic knowledge to achieve effective communication.

\subsection{Religious nursing status abroad}

Culliford [8] believes the advantages of the religious spirit in nursing are mainly embodied in three aspects: (1) Conducive in preventing disease; (2) Conducive in speeding up recovery; (3) Conducive in disease control. Veronlca Green [8] points out those nursing measures shall be distinguished on account of different religious beliefs and different diseases. In 2009, On Religion Caring, Kirstine Griffith [9] puts forward that nurses should provide good care through following methods of the patient with religious beliefs which includes mental concern and religion custom support, respect of differences on religion, respect of individuality of each person, keeping an open attitude, making any rational hypothesis; actively listening and observing patients' verbal and non-verbal response.

\subsection{Having self-esteem of religious faith}

Every religious belief is of the opinion that people have different degrees of faith related self-esteem. In China, religious believers are in the minority, while more people neither know nor understand religious belief. In most cases, the religious always live with other non-believers after they are hospitalized. They yearn for others' understanding and respect, but not discrimination or satire. Especially for introvert patients, they will feel repressed for lack of other people's understanding.

\subsection{Unique psychological comforting}

General patients' mental states are like melancholy, dysphoria, loneliness and depression, etc. They lack psychological comforting, while religious beliefs are of the opinion that patients can look forward and depend on a higher order for their beliefs. Some of the patients accept religious belief when they are in pain and cannot liberate mentally, and they will treat disease and death from different angles rather than avoiding these topics. They will treat misfortune from the religious angle and adjust their view of life and value, which make their mood peaceful with no unnecessary fear of the disease, lowering mental stress and reducing some unhealthy psychological reactions at the same time.

\subsection{Unconventional thanatopsis}

Many people are fearful of death, especially critical patients. Some terminal cancer patients are pessimistic and in a stage of hopelessness, and they neither accept retreatment nor accept others' comfort, even sinking into a state of waiting for death. However, some religious belief determine that patients are brave enough to face this issue, as they are calm and positive. Take a Christian patient for instance, her stomach cancer metastasis happened several times during four years after she accepted the stomach operation. However, she said: "Now I want nothing, and when the day comes I will go back to heaven happily." From these words we can find out her attitude to death [10].

\subsection{Respecting patient's belief}

First, nurses shall strengthen the study of all aspects, increase knowledge reserve, especially the knowledge on religious aspect, and make full sense of patient's mental activity. Patients may think highly of their belief and sometimes even exceed the disease itself. It will be menticide to patients if nurses have improper words or behaviors. Therefore, nurses shall respect their beliefs sufficiently and show understanding in words and deeds. Nurses shall listen to patients carefully when they talking about issues on religious beliefs, and comfort them with their religion believes at the right time.

\subsection{Handling contradiction between religion activi- ties and ward management}

For example, Buddhists plays chant sutras when approaching their end, cover bright yellow sheets on the bedding, and even burn joss sticks and kowtow in the ward which has strong impact on the ward's administrative order, and harmful effect to other patients' mental state. In such cases, we should make proper adjustment and arrangement, and fulfill their mental demands at our best without influencing other patients.

\section{Multicultural nursing demand of religion believing patient}

5.1. Diet

Nurses shall respect different dietary habits of each religion. Like considerable proportion of modern Christians are vegetarians, and they do not eat pork especially. Nurses should pay attention to patients' living habits, especially the diet habit during the nursing process. 


\subsection{Custom}

Religion has its own customs. Take Muslims for instance, all the Muslim men must accept circumcision, and the Muslim regions of China also regard a boy's circumcision as important. Medical staff shall know and respect Muslim custom.

\subsection{Privacy}

Taking an example from Islam, privacy for the female patient is very important, and nurses should pay special attention to female patients' privacy when taking care of them. Nurses shall insulate patient's bed and cover it tightly. Apart from husband and close relatives, the Muslim female cannot stay with other men alone, therefore a female nurse should be taking care of the female patient [11].

\subsection{Religion activities}

Every religion has its own specific religious activity, such as Christian liturgy. Nurses should respect the religious custom, and stagger the treatment time according to the praying time, and arrange another room for use for fear of affecting other patients.

\section{Conclusion}

In conclusion, this paper focuses on religion and multiculturalism, with research status on religious nursing at home and abroad, analysis of clinical nursing practices for religion believing patients, further discussing nursing in multicultural religion believing patients. At present, the development of special nursing on religion belief is lagging. Nurses should empathize with patients, and strengthen their respect and understanding in religious believers and humanistic care. We sincerely hope that in the near future, each religion believing patient can seek medical treatment from every hospital easily without worrying about religion belief problem, getting comfort on spiritual as well as get medical aspects of the treatment of their bodies.

\section{Conflicts of interest}

These authors have no conflicts of interest to declare.

\section{Authors' contributions}

These authors contributed equally to this work.

\section{References}

1. Wang L. Talking about application of polynary cultural nursing in wards. Chinese Nursing Research. 2006;14(8):74-82.

2. Wu $\mathrm{C}$ and Yang $\mathrm{H}$. Importance of culture diversity in clinical nursing. Journal of Modern Nursing. 2004;19(28):562-565.

3. Wang X. Fifteen lessons on religion basis. Beijing: Peking University Press. 2003.

4. Hu Z, Zhu D. Intercultural education of nursing teaching. Journal of Nursing Science. 2005;22(4):373.

5. Deng $X$. Eleven lessons on contrastive study of Western and Chinese cultures. Changsha: Hunan Education Publishing House. 2007.

6. Culliford L. Spirituality and clinical Care. BMJ. 2002;325:1434-1435.

7. Bentley S. Religions of our Neighbors. Volumes I-VIII. Bentley West Publishing Co. Coquitlam. B.C. 2007.

8. Brown J. The Spiritual Legacy of the American Indian. Crossroad, N.Y. 1999.

9. Burgess SM, McGee GB. Dictionary of Pentecostal and Charismatic Movements. Zondervan Publishing House. Grand Rapids, Michigan. 1988.

10. Church J. Handbook: Caring for the Culturally Diverse Elderly. Carewest Administration Center. Calgary, Alberta. 2000.

11. Coward H. Life after Death in World Religions. Orbis Books, Maryknoll. New York. 2007. 